\title{
THE EFFECT OF GLYCEROL CONCENTRATION IN TRIS GLUCOSE EGG YOLK EXTENDER ON THE QUALITY OF TIMOR DEER FROZEN SEMEN
}

\author{
W. M. M. Nalley ${ }^{1}$, R. Handarini ${ }^{2}$, T. L. Yusuf ${ }^{3}$, B. Purwantara ${ }^{3}$ and G. Semiadi ${ }^{4}$ \\ ${ }^{1}$ Faculty of Animal Science, Nusa Cendana University, \\ Jl. Adi Sucipto Penfui Kupang, East Nusa Tenggara - Indonesia. \\ ${ }^{2}$ Faculty of Agriculture, North Sumatra University, \\ Jl. dr. Sofyan No.3 Kampus USU Padang Bulan, Medan 20154 - Indonesia \\ ${ }^{3}$ Faculty of Veterinary Medicine, Bogor Agricultural University, \\ Darmaga Campus, Bogor 16680 - Indonesia \\ ${ }^{4}$ Research Center for Biology, \\ Jl Raya Cibinong Km. 46, Cibinong, Bogor-Indonesia \\ Corresponding E-mail: marlenenalley@yahoo.com
}

Received December 13, 2010; Accepted April 6, 2011

\begin{abstract}
The aims of study was to compare the glycerol concentration in Tris glucose egg yolk (TGEY) diluents on the quality of deer frozen semen. Semen was collected from 5 Timor deer using electroejaculator. Immediately after collection the semen was evaluated macroscopic and microscopically. After initial evaluation, the semen was divided into three tubes and extended with Tris egg yolk with three different glycerol concentrations, which were 10\% (TGEY $\left.{ }_{10}\right) ; 12 \%\left(\right.$ TGEY $\left._{12}\right)$ and $14 \%$ (TGEY $\left.{ }_{14}\right)$. The sperm motility, viability, acrosome intact and membrane intact were evaluated in raw semen, after equilibration and after thawing. The results showed that there were no differences (p>0.05) on the sperm motility, viability as well as sperm acrosome intact. Sperm membrane intact in TGEY $_{10}(52.50 \pm 5.89 \%)$ and TGEY $_{14}(51.50 \pm 4.12 \%)$ were higher $(\mathrm{p}<0.05)$ than in TGEY $_{12}$ (49.00 \pm 6.58$)$. It was concluded that 10,12 or $14 \%$ glycerol concentration can be used for Timor deer semen cryopreservation.
\end{abstract}

Keywords: glucose, glycerol, Timor deer semen, Tris

\section{INTRODUCTION}

Cryopreservation of spermatozoa from endangered species is a valuable tool for genetic management. Semen preservation and artificial insemination could become powerful tools for the genetic management of deer semen programmers since these assisted reproductive techniques that would allow the storage of semen from genetically valuable animals (Watson and Holt, 2001).

Few studies have addressed on semen preservation in deer. Soler et al. (2003) reported the effect of thawing in red deer (Cervus elaphus), fallow deer (Dama dama) and Pe're David's deer (Elaphurus davidianus). Zomborszky et al. (2005) applied the cryopreservation of sperm obtain from cauda epididymis and vas defferentes of red deer (Cervus elaphus hippelaphus) and fallow deer (Dama dama). Martınez-Pastor et al. (2009) tested extenders and freezing protocols for
Iberian red deer (Cervus elaphus hispanicus) semen.

Damage of sperm during cryopreservation has been attributed to cold shock, ice crystal formation, oxidative stress, membrane alteration, cryoprotectant toxicity, and osmotic changes (Watson, 1995). The survival of spermatozoa during freezing and thawing is affected by many factors, such as cyoprotectan, equilibration time, including the composition of the cryodiluent (Watson, 2000; Leibo and Songsasen, 2002). The amount of glycerol and the presence or absence of sugars in the cryodiluent, may also be important (Salamon and Maxwell, 2000; Cheng et al., 2004). Glycerol is considered the most effective cryoprotectant for ruminants (Leibo and Songsasen, 2002). Nevertheless, an optimal concentration for Timor deer (Cervus timorensis) species has not been defined. The aim of this study was to evaluate the quality of Timor deer semen on Tris glucose egg yolk extender with different glycerol concentration. 


\section{MATERIALS AND METHODS}

\section{Reagents and Media}

All chemicals were obtained from Merck, Germany. Tris buffer was prepared by mixing $3.36 \mathrm{~g}$ Tris (hydroxymethyl aminomethane), monohydrate citric acid $1.99 \mathrm{~g}$ and $0.5 \mathrm{~g}$ glucose dissolved in $100 \mathrm{~mL}$ aquadest (Asher et al. 2000). There were three extenders: Tris glucose egg yolk Glucose (TGEY) added by glycerol $10 \%$ $\left(\right.$ TGEY $\left._{10}\right)$, glycerol $12 \%\left(\right.$ TGEY $\left._{12}\right)$ or glycerol $14 \%$ (TGEY $\left.{ }_{14}\right)$ (Table 1).

\section{Semen sample}

Samples were obtained every three weeks from 5 mature Timor deer (Cervus timorensis). A total of 50 ejaculates were individually frozen (Ten replications from each of five stags). Animals (4-5 years-old; $64-102 \mathrm{~kg}$ body weight) were housed in a semi-free ranging regime at private farm at Pondok Gede. In order to prevent variations due to multiple electroejaculations, the samples used in this study were always obtained from the first electroejaculation. Stags were restrained and anaesthetized by an intramuscular injection of $1 \mathrm{mg}$ xylazine and $2 \mathrm{mg}$ ketamin/ $/ \mathrm{kg}$ body weight (Fletcher, 2001). The rectum was cleaned from feces and the prepuce area was shaved and washed with physiological saline. Electroejaculation was performed using a rectal probe which was connected to a battery power source that allowed to control the voltage and ampere. Ejaculation occurred in the average values of 2 to 18 voltages.

\section{Semen evaluation and processing}

The semen samples were assessed for volume, color, consistency, mass activity, sperm concentration, sperm morphology, sperm viability and the percentage of motile sperm, sperm with membrane intact (MI) and sperm with acrosome intact (AI). Only ejaculates with a concentration more than $500 \times 10^{6}$ sperm $/ \mathrm{mL}$, having $>65 \%$ progressively motile sperm and $>80 \%$ of the sperm with normal morphology were selected for this study.

After evaluation, each of raw semen was equally divided into three tubes, and diluted in one of three extenders: TGEY $_{10}$, TGEY $_{12}$ or TGEY $_{14}$ to reach the total semen concentration of $100 \times 10^{6} / \mathrm{mL}\left(25 \times 10^{6} /\right.$ straw $)$. The extended semen was individually packaged in $0.25 \mathrm{ml}$ straws, and equilibrated at $4^{\circ} \mathrm{C}$ for 4 hours. The straw was frozen in a styrofoam box at $5 \mathrm{~cm}$ above the liquid nitrogen surface for 10 minutes. The frozen semen was stored for 24 hours in liquid nitrogen for further evaluations. The frozen semen straws were placed in a $37^{\circ} \mathrm{C}$ water bath for 30 second and then the contents was poured into a glass tube.

\section{Assessment of the quality}

The percentage of motile, viable, MI and AI sperm were evaluated after diluted, after equilibrated and after thawed. The motile sperm was evaluated by mixing the semen gently and placing a $10 \mu \mathrm{L}$ drop of semen on a warm slide and covered with a glass cover slip $(18 \mathrm{x} 18 \mathrm{~mm})$ from five selected representative fields. The mean of the five estimations was recorded as final motility score. Sperm viability was assessed using eosin-nigrosin stain (Bart and Oko, 1989), by diluting $10 \mu \mathrm{L}$ drop semen on a slide glass and adding $40 \mu \mathrm{L}$ drop of eosin-nigrosin, and then was smeared on a new slide glass and dried quickly in heating stage $\left(37^{\circ} \mathrm{C}\right)$. Microscopes observation area were selected randomly from ten fields, with total of 200 cells. Individual sperm were recorded as being viable (unstained) or dead (stained). Samples were also taken to assess membrane integrity by means of the hypoosmotic swelling (HOS) test. Briefly, $5 \mathrm{~mL}$ of diluted sperm suspension was mixed by $50 \mathrm{~mL}$ of hypo-osmotic sodium citrate solution (100 $\mathrm{mOsmol} / \mathrm{L}$ ) and was incubated the mixture at room temperature for $30 \mathrm{~min}$ and was evaluated

Table 1. Extender Composition (v/v)

\begin{tabular}{lccc}
\hline \multicolumn{1}{c}{ Component } & TGEY $_{10}$ & TGEY $_{12}$ & TGEY $_{14}$ \\
\hline Buffer Tris (\%) & 70 & 68 & 66 \\
Egg yolk (\%) & 20 & 20 & 20 \\
Glycerol $(\%)$ & 10 & 12 & 14 \\
\hline
\end{tabular}

TGEY $_{10}$ (Tris glucose egg yolk glycerol 10\%; Tris glucose egg yolk glycerol 12\% (TGEY $_{12}$ ) and Tris glucose egg yolk glycerol 14\% $\left(\right.$ TGEY $\left._{14}\right)$ 
under Olympus microscope $\mathrm{CH} 20$ at 400 magnifications (Fonseca et al., 2005). The sperm membrane was considered membrane intact if the sperm tail coiled at the end of the assay and the result was expressed as HOS positive (\%). For acrosome integrity, stained smears were prepared according to Nagy et al. (2001).

\section{Statistical Analysis}

Data were statistically analyzed using a oneway analysis of variance, followed by the Duncan's Multiple Range Test to determine significant differences in all the parameters between groups using the SPSS software system (Version 17.0). Differences with values of $\mathrm{P}<$ 0.05 were considered to be statistically significant.

\section{RESULTS AND DISCUSSION}

Raw semen demonstrated a variation in the quality between the stags. The average of semen volume was $2.84 \pm 0.92 \mathrm{~mL}$, it was cloudy to creamy white in color, $7.31 \pm 0.33$ of $\mathrm{pH}$, and having thin to thick in consistency. The mean of mass activity was $2.7 \pm 0.46$ with the percentage of sperm abnormality was $9.40 \pm 0.94 \%$ and $1200.50 \pm 139.57$ million $/ \mathrm{mL}$ in sperm concentration. The percentage of motile, viable sperm, membrane and acrosome intact were $76.5 \pm 4.74 ; \quad 84.32 \pm 4.49 \% ; \quad 77.23 \pm 6.12 \%$ and $79.79 \pm 4.36 \%$, respectively (Table 2 )

After 4 hours equibration, the sperm motility, viability, membrane and acrosome intact of the sperm were found no differences ( $p>0.05$ ), compared to those in raw semen. The sperm quality after equilibration decreased by 5.50 to $8.00 \%$ on the sperm motility and 5.60 to $7.68 \%$ on viable sperm. The membrane intact and acrosome intact decreased by 4.60 to $6.16 \%$ and 6.27 to $7.46 \%$, respectively. There were no significant differences $(\mathrm{P}>0.05)$ on the quality of deer semen after thawing. The range of sperm motility and viability were 49 to $52.50 \%$ and 58.32 to $63.93 \%$ respectively. This finding was demonstrated by membrane and acrosome intact as well, with the range of 45.22 to $54.30 \%$ and 53.25 to $56.7 \%$, respectively (Table 2 ).

Indirectly, analyzes of sperm motility are expected to provide cues on the potential fertility of spermatozoa. Decreasing the sperm motility during freezing were highly significant $(\mathrm{P}<0.01)$.

Table2. The Quality of Deer Semen after Thawing in Tris Glucose Egg yolk with Different Glycerol Concentration

\begin{tabular}{lccc}
\hline \multirow{2}{*}{ Parameter } & \multicolumn{3}{c}{ Glycerol Concentration } \\
\cline { 2 - 4 } & & $10 \%$ & $14,00 \%$ \\
Motile sperm (\%) & $76.50 \pm 4.74^{\mathrm{a}}$ & Raw semen \\
Viable sperm (\%) & $84.32 \pm 4.49^{\mathrm{a}}$ & $84.32 \pm 4.49^{\mathrm{a}}$ & $76.50 \pm 4.74^{\mathrm{a}}$ \\
Membrane intact (\%) & $77.23 \pm 6.12^{\mathrm{a}}$ & $77.23 \pm 6.12^{\mathrm{a}}$ & $84.32 \pm 4.49^{\mathrm{a}}$ \\
Acrosome intact (\%) & $79.79 \pm 4.36^{\mathrm{a}}$ & $79.79 \pm 4.36^{\mathrm{a}}$ & $77.23 \pm 6.12^{\mathrm{a}}$ \\
& & After equilibration & \\
Motile sperm (\%) & $68.50 \pm 7.09^{\mathrm{a}}$ & $68.50 \pm 5.80^{\mathrm{a}}$ & $71.00 \pm 5.16^{\mathrm{a}}$ \\
Viable sperm (\%) & $77.55 \pm 5.74^{\mathrm{a}}$ & $76.63 \pm 4.25^{\mathrm{a}}$ & $78.51 \pm 3.82^{\mathrm{a}}$ \\
Membrane intact (\%) & $70.57 \pm 7.25^{\mathrm{a}}$ & $71.86 \pm 4.40^{\mathrm{a}}$ & $72.13 \pm 5.39^{\mathrm{a}}$ \\
Acrosome intact (\%) & $73.90 \pm 6.35^{\mathrm{a}}$ & $72.71 \pm 3.95^{\mathrm{a}}$ & $73.72 \pm 4.78^{\mathrm{a}}$ \\
& & After thawing & \\
Motile sperm (\%) & $52.50 \pm 5.89^{\mathrm{a}}$ & $49.00 \pm 6.58^{\mathrm{a}}$ & $51.50 \pm 4.12^{\mathrm{a}}$ \\
Viable sperm (\%) & $63.93 \pm 7.23^{\mathrm{a}}$ & $58.32 \pm 6.78^{\mathrm{a}}$ & $61.10 \pm 6.65^{\mathrm{a}}$ \\
Membrane intact (\%) & $54.30 \pm 6.37^{\mathrm{a}}$ & $45.22 \pm 12.02^{\mathrm{b}}$ & $54.08 \pm 8.42^{\mathrm{a}}$ \\
Acrosome intact (\%) & $55.53 \pm 6.69^{\mathrm{a}}$ & $53.25 \pm 10.49^{\mathrm{a}}$ & $56.70 \pm 8.73^{\mathrm{a}}$ \\
\hline
\end{tabular}

Superscript in the same row indicates significantly differences $(p<0.05)$ 
Table 3. The Sperm Motility on Raw Semen, After Equilibration and After Thawing of Timor Deer Extended in Tris Glucose Egg Yolk with Different Glycerol Concentration

\begin{tabular}{llll}
\hline & \multicolumn{3}{c}{ Extender } \\
\cline { 2 - 4 } & TGEY $_{10}$ & TGEY $_{12}$ & TGEY $_{14}$ \\
\hline Raw semen & $76.50 \pm 4.50^{\mathrm{a}}$ & $76.50 \pm 4.50^{\mathrm{a}}$ & $76.50 \pm 4.50^{\mathrm{a}}$ \\
After equilibration & $68.50 \pm 7.09^{\mathrm{b}}$ & $68.50 \pm 5.80^{\mathrm{b}}$ & $71.00 \pm 5.16^{\mathrm{b}}$ \\
After thawing & $52.50 \pm 5.89^{\mathrm{c}}$ & $49.00 \pm 6.58^{\mathrm{c}}$ & $51.50 \pm 4.12^{\mathrm{c}}$ \\
Recovery rate $(\%)$ & 68.63 & 64.05 & 67.32 \\
\hline
\end{tabular}

Superscript in the same row indicates significantly differences $(\mathrm{p}<0.05)$

As mentioned before, the motility decreased during equilibration, but the high level of decrease demostrated during freezing and thawing by 16 to $19.50 \%$. The freezability of sperm was indicated in recovery rate (RR) value. Recovery rate was measured by dividing after thaw to raw semen motility and multiplied by $100 \%$ (Hafez, 1993). The RR of three different glycerol concentrations in Tris Egg yolk glucose was similar those were $68.63 \%$ (TGEY ${ }_{10}$ ), $64.05 \%\left(\right.$ TGEY $\left._{12}\right)$ and $67.32 \% \quad\left(\right.$ TGEY $\left._{14}\right)$, respectively (Table 3 ).

Post thawed motility of 49 to $52.50 \%$ obtained in this study was higher than those in research of Martınez-Pastor et al. (2009) on Iberian deer in Trilady extender which was only $42.20 \pm 4.80 \%$. After thawed motility was also influenced by source of sperm. Fernandez-Santos et al. (2007) reported that after thaw motility was $61.10 \pm 2.90 \%$, if the sperm obtained from epididymal. The cryopreservation can be affected by various extender components such as buffer system, concentrations of egg yolk or glycerol, or the inclusion of different types of sugars (Salamon and Maxwell, 2000; Leibo and Songsasen, 2002).

The extender composition in this study consisted of Tris which was known as universal buffer and widely used for farm animals including buck and bull semen (Yusuf et al. 2006; Arifiantini and Purwantara, 2010). Egg-yolk is considered to be a beneficial component of freezing extenders, probably by stimulating adenylatecyclase and stimulating the sperm motility (Okamura et al. 1991). Lipoproteins from egg-yolk are proven to prevent spermatozoa from cold shock (Manjunath et al., 2002). Glucose as monosaccharides preserved spermatozoa, whereas fructose improved acrosomal and mitochondrial status, mannose and glucose showed a membranestabilizing ability (Nicolajsen and Hvidt, 1994). Glucose addition to the extender conferred better improvement in forward motility percentage than the other disaccharides addition after cryopreservation in Boer goat (Naing et al., 2010). Sugars performed several functions in the extender, such as adding osmotic pressure to the medium and act as cryoprotectants (Watson, 1979). The main effect of sugars and glycerol is their ability to replace the water molecule and stabilize the membrane during transition through the critical temperature zones (Crowe and Crowe, 1984; Crowe et al. 1985).

Glycerol is commonly used as a permeating cryoprotectant in sperm freezing; its toxicity can cause loss in sperm viability and fertility (Rudenko et al. 1984). According to Asher et al. (1992) cited by Semiadi (1998), the sperm motility after freezing decreased only $14 \%$ by adding $14 \%$ glycerol concentration to TEY extender. There were no differences on the semen quality of Iberian red deer (Cervus elapsus hispanicus) after freezing by adding 4 or $8 \%$ glycerol concentration in TEY extender (Garde 2000). The glycerol concentration in this study was higher compared to bull, ram or stallion frozen semen (Van Wagtendonk-Leeuw et al. 2000; Soylu et al. 2007; Azizah and Arifiantini, 2009). The result of this study indicated that 10 , 12 or $14 \%$ of glycerol concentration can be used for freezing Timor deer spermatozoa with comparable post thawed quality.

\section{CONCLUSION}

It was concluded that 10,12 or $14 \%$ of glycerol concentration in Tris egg yolk glucose was suitable for Timor deer cryopreservation. 


\section{ACKNOWLEDGMENT}

This work was supported by Directorate of Higher Education "Hibah Pasca" grant. The authors thank to Ari, D.V.M. and Bondan Achmadi for expert of handling animals and the assistance.

\section{REFERENCES}

Arifiantini, R.I. and B. Purwantara. 2010. Motility and viability of Friesian Holstein Spermatozoa in Three Different extender Stored at $5^{\circ} \mathrm{C}$. J. Indonesian Trop. Anim. Agric. 35(4):1-5

Asher, G.W., D.K. Berg and G. Evans. 2000. Storage of semen and artificial insemination in deer. Anim. Reprod. Sci. 62:195-211

Azizah and R.I. Arifiantini. 2009. Kualitas semen beku kuda pada pengencer susu skim dengan konsentrasi gliserol yang berbeda. J. Vet. 10: 3-7

Cheng, F.P., J.T. Wu, J.P. Chan, J.S. Wang, H.P. Fung, B. Colenbrander and K.C. Tung. 2004. The effect of different extenders on post-thaw sperm survival, acrosomal integrity and longevity in cryopreserved semen of Formosan Sika deer and Formosan Sambar deer. Theriogenology. 61:1605-1616

Crowe, J.H. and L.M. Crowe. 1984. Effect of dehydration on membranes and membrane stabilization at low water activities. In: Chapman, D. Ed. Biological Membranes. Academic Press, New York, pp. 57-103

Crowe, J.H., L.M. Crowe and D. Chapman. 1985. Interaction of carbohydrates with dry dipalmitoyl phosphatidylcholine. Arch. Biochem. Biophys. 236:289-296

Fernandez-Santos, M.R., M.C. Esteso, V. Montoro, A.J. Soler and J.J. Garde. 2006. Cryopreservation of Iberian red deer (Cervus elaphus hispanicus) epididymal spermatozoa: Effects of egg yolk, glycerol and cooling rate. Theriogenology. 66: 1931-1942

Fletcher, T.J. 2001. Farmed deer: new domestic animals defined by controlled breeding. Reprod. Fertil. Dev.13:511-516

Fonseca, J.F., C.A.A. Torres, V.V. Maffili, A.M. Borges, A.D.F. Santos, M. T. Rodrigues, and R.F.M. Oliveira. 2005. The hypoosmotic swelling test in fresh goat spermatozoa Anim. Reprod. 2(2): 139-144

Garde, J., E. Anel, A. Garcia-Diaz, J.C. Boixo, A. Soler, P. de Paz, A. Lopez-saez, C. Guerra, and L. Anel. 2000. Evaluation of two glycerol concentration in freezing of electroejaculated and apididimal spermatozoa from iberian rusa merah (Cervus elaphus hispanicus). $14^{\text {th }}$ International Congress on Animal Reproduction Stockholm, 2-6 July 2000. Page 142

Hafez, E.S.E. 1993. Gamete preservation. In: Hafez, E.S.E. 1993. Reproduction in Farm Animals. Philadelphia: Lea and Febiger.

Leibo, S.P and H. Songsasen. 2002. Cryopreservation of gametes and embryos of non-domestic species. Theriogenology. 57:303-326

Manjunath, P., V. Nauc, A. Bergeron and M. Ménard. 2002. Major proteins of bovine seminal plasmabind to the low-density lipoprotein fraction of hen's egg yolk. J. Biol. Reprod. 67:1250- 1258

Nagy, S., A. Kovacs, T. Zubor, Z. Zomborszky, J. Toth and P. Horn. 2001. Evaluation of membrane integrity of frozen/thawed deer spermatozoa: short communication. Acta. Vet. Hung. 49 (2):223-227

Naing, S.W., H. Wahid, K.M. Azam, Y. Rosnina, A.B. Zuki, S. Kazhala, M.M. Bukara, M. Thein, T. Kyaw and M.M. San 2010. Effect of sugars on characteristics of Boer goat semen after cryopreservation. Anim. Reprod. Sci. 122: 23-28

Nicolajsen, H and A. Hvidt. 1994. Phase behaviour of the system trehalose- $\mathrm{NaCl}-$ water. Cryobiology. 31:199-205

Okamura, N., Y. Tajima, S. Onoe and Y. Sugita. 1991. Purification of bicarbonate-sensitive sperm adenylylcyclase by 4-acetamido-40isothiocyanostilbene-2,20-disulfonic acidaffinity chromatography. J. Biol. Chem. 25:17754-9

Rudenko, S.V., S.D. Gapochenko and V.A. Bondarenko. 1984. Effect of glycerol on the capacitance and conductivity of bilayer lipid membranes. Biophysics 29:245-249

Salamon, S and W.M.C Maxwell. 2000. Storage of ram semen. Anim. Reprod. Sci. 62; 77-111

Semiadi, G., P.D Muir, T.N Barry and G. Asher. 1998. Produksi semen rusa sambar jantan dan tanggapan terhadap penyerentakan berahi rusa sambar betina. Med. Vet. 5:11-16

Soler A.J., V. Astore, A. Sestelo, M. Rivolta, L.N. Jacome and J.J. Garde. 2003. Effect of thawing procedure on cryosurvival of deer spermatozoa: work in progress Theriogenology $60: 511-520$ 
Soylu, M.K., Z. Nur, B. Ustuner, I. Dogan, H. Sagirkaya, U. Gunay and A.K. Kemal. 2007. Effects of various cryoprotective agents and extender osmolality on post-thawed ram semen. Bull. Vet. Inst. Pulawy. 51:241-246

Yusuf, T.L., R.I. Arifiantini and N. Rahmiwati.
2005. Daya Tahan Semen Cair Kambing Peranakan Etawah dalam Pengencer Kuning Telur dengan Kemasan dan Konsentrasi Spermatozoa yang Berbeda. J. Pengembangan Peternakan Tropis. 30(4): 217-223 